\title{
A comparison of the application potential of waterborne platooning for the Danube and the Rhine corridors
}

\author{
A. Colling ${ }^{1 *}$, R. Hekkenberg ${ }^{1}$, E. van Hassel ${ }^{2^{*}} \mathbb{D}$, M. Vidić ${ }^{3}$ and I. Bačkalov ${ }^{3}$
}

\begin{abstract}
Objective: This study investigates the implementation of the waterborne platooning transport concept in two of the largest European inland navigation corridors, the Rhine and the Danube region. Each region has different geoeconomic and environmental features. These features are compared, and their effects on implementing a waterborne platooning transport concept are studied. The waterborne platooning concept, referred to as the Vessel Train, aims to reduce crew cost by automating the navigation tasks and moving the navigational responsibility to the leading vessel of the platoon, which is fully manned.

Methods: The implementation of the Vessel Train is assessed by making use of a developed model, which allows the assessment of the concept's viability by comparing the annual cost per transported ton of a reference vessel that sails individually to a vessel that sails as a part of a VT on the same route.

Results: The results conclude that the application of waterborne platooning on the Rhine is more promising than on the Danube. The low wages hamper the implementation of the concept on the Danube in the region, the low traffic density on the waterway, and the common use of large push tows instead of self-propelled vessels.

Implications for research: As determined in the analysis for the Rhine case, a reduction in transport cost would make waterborne transport more attractive. However, other factors, such as the further integration of the VT in the overall supply chain, play a role in the successful implementation of this IVT transport concept. Applying the VT concept in the Danube case requires more potential cargo flows, which can be obtained by adding push convoys into the vessel train. This way of transport is more numerous on the Danube than self-propelled vessels. Both of these aspects should be studied further.
\end{abstract}

Keywords: Rhine corridor, Danube corridor, Waterborne platoon, Reduced crew cost, Inland navigation

\section{Introduction}

An innovative transport system is being developed by the NOVIMAR project [38] that aims to enhance waterborne transportation in different areas in Europe through crew cost minimization. It aims to do so via the Vessel Train (VT) concept that is a platoon of self-propelled vessels.

\footnotetext{
*Correspondence: a.p.colling@tudelft.nl; edwin.vanhassel@uantwerpen.be ${ }^{1}$ Delft University of Technology, Mekelweg 2, 2628 CD Delft, The Netherlands

${ }^{2}$ University of Antwerp, Prinsstraat 13, 2000 Antwerp, Belgium Full list of author information is available at the end of the article
}

\subsection{The VT concept}

A VT consists of a fully manned Lead Vessel (LV) equipped with navigation and control systems. It takes over situational awareness and navigation responsibility for the vessels following it while they sail in the platoon. This means that this transfer of navigational tasks from the Follower Vessel (FV) to the LV enables crew size reduction, allowing vessel operations with smaller crews and contributing to a cost reduction.

The VT service is comparable to that of a train that has a predictable itinerary. In this article's assessment, these 
operational conditions are achieved by setting a regular liner departure schedule on a predefined stretch of waterway. It allows the users to join/leave the train at a point of their choice.

The departure intervals, together with a VT, a potential lower operating speed, increase voyage times for the VT user. This lower operating speed is caused by the fact that the speed of VT is determined by the vessel with the lowest operational speed, causing other vessels to slow down while operating in the VT. The VT concept can only work if the cost of the VT control system and the cost created by these increased voyage times do not outweigh the savings that are achieved by the crew reduction. More information and details regarding the VT can be found in NOVIMAR [38].

\subsection{Background}

As advocated by Sys et al. [45], sustainability is becoming increasingly important in the transport sector and thus also in the European inland navigation sector. Therefore different policy packages have been developed to make the inland navigation sector more competitive against other modes of transport so that there would be an increase in its market share. However, the ton.km performed by the inland navigation sector is even decreasing in absolute terms (especially the dry bulk sector in western Europe), and also its market share is diminishing [22].

One of the reasons for this relatively poor performance of the IWT sector could be due to the fact that it is due to different barriers. Rogerson [43] identified, via a literature study, them as regulatory, financial, service quality, and market characteristic boundary conditions. Next to these barriers also the relative poor ecological performance of the IWT sector is mentioned. Caris et al. [10] also identified that a lack of good integration of IWT in the supply chains is one of the reasons for its poor performance. These factors also play a role in the mode choice of a shipper, next to generalized transport cost.

In order to overcome (some) of the above-mentioned challenges, researchers also have looked into the application of alternative waterborne concepts in different operating corridors. Charles [11] demonstrates under which conditions sea-river vessels are more efficient than "barge + short sea" solutions, as they can avoid seaport transshipment and hence can lower transport costs. Konings and Ludema [31] focus on the restrictions that river conditions impose on the use of sea-river ships and suggest a solution that makes use of specially designed push barges to face these limitations. They assess the competitiveness of the concepts for the UK- Germany corridor and compare it to other modes of transport. These two cases show the possible larger application area of the VT concept.
Another challenge facing the IWT sector is the lack of skilled crew members. The labour shortage in the (western) European IWT sector is growing. It will be rather more challenging to replace the aging crew of the Rhine fleet with human crews [48]. The level of conservatism can be relatively high. Existing operators and other actors will doubt the safety and reliability of all the newly developed technologies.

Therefore, technology that will allow vessel operations with fewer crew members could not only be seen as a (transport) cost-saving development but also as a way to deal with a smaller pool of crew members. The VT technology could allow vessel operations with a smaller crew. The VT operations could therefore be seen as an intermediate step between current operations of the inland vessels and full autonomous inland vessels.

Waterborne platooning has so far been researched by Chen et al. [12-14], studying the application of the principles for autonomous vessels. Meersman et al. [35] researched the semi-autonomous application of the VT, presenting direct and societal costs. It provides a variety of different scenarios in which the FVs could choose to join the VT for individual trips. Colling and Hekkenberg [15] and Colling et al. [16] additionally address the waiting time created by the VT implementations, as well as the VT benefits created by exploiting different operating modes and the effects of imposing a VT operating speed. The research presented in the present article builds on this research by identifying differences in the VT success factors requirements when the concept is implemented in a different geographical area. A similar approach has been done by Notteboom et al. [37], in which they compare the container barge networks of the Yangtze river and the Rhine. Similar to the comparison in this article, they have identified geographical/nautical and macro-economic aspects, but also governance factors that influence the development of the inland sector and the associated inland ports in the respective region.

\subsection{Research focus}

The research focus of this article is to demonstrate to what extent the VT's implementation needs can be met in different geographical areas, namely the Rhine and the Danube corridor. It follows up on the existing studies Colling and Hekkenberg $[15,16]$ by adding environmental factors and emphases geo-economic condition adaptations for the VT concept. The main questions answered are:

- What are the most important geographical and geoeconomic impact factors affecting the implementation of the VT? 
- How do these factors differ for the Rhine and the Danube inland navigational corridors?

- What are the resulting viability requirements of the $V T$ implementation for the respective regions?

The structure of this article is organized into six sections. Section 2 is a literature review, gathering corridor feature data. Section 3 provides a brief summary of the assessment method to identify the viability requirements for an application of the VT. All specific input data for the case studies are provided in Sect. 4; before presenting the case studies, sensitivity analysis and viability requirement results in Sect. 5. Lastly, the article is rounded up with conclusions and discussion in Sect. 6.

\section{The Rhine and the Danube corridors}

This section first discusses the differences of geographical river characteristics and environmental effects between the Rhine and the Danube corridor. The main reason to discuss these two regions is due to the fact that observed from the research performed since the end of the Cold War has identified the rift that the era has caused the development of the transportation sector in both European regions, such as discussed by Hall [27]. Furthermore, historical differences have caused the business structure and types of vessels used for waterborne freight transport to develop differently in the South-eastern European inland corridors and the Central European in terms of business structure and traffic density.

Then the focus is shifted to geo-economic and geopolitical differences. The results from this section will be used to define case studies for a quantitative comparison in Sect. 5.

\subsection{Corridor differences for the VT deployment 2.1.1 Crew requirements and wages}

A clear difference between wages in Rhine and Danube countries can still be identified today in both the inland waterway cruise sector [20], and in the freight transport sector [19]. These wages are relevant for the VT concept since the crew cost reduction is one of the main economic benefits of the concept, where, if the crew wages are low, the main direct economic benefit of the VT concept will be small because only a small amount of direct cost for the vessel owner can be saved.

There are no uniform European-wide regulations that identify the size and composition of crews. This usually falls under the responsibilities of the states in which the vessels are sailing [19]. While for the Rhine the CCNR provides guidelines [7], the Danube Countries follow the guidelines provided by UNECE Resolution No. 61 [46].
Table 1 Minimum manning requirements

\begin{tabular}{llllll}
\hline Role & \multicolumn{2}{c}{ Class V } & & & \multicolumn{2}{c}{ Class IV } \\
\cline { 2 - 3 } \cline { 6 - 6 } & A1 & & & A1 & B \\
\hline Boat master & 1 & 2 & 1 & 2 \\
Helmsman & 1 & 1 & & \\
Boatman & & 1 & 1 & 1 \\
$\begin{array}{l}\text { Apprentice } \\
\text { Total Required crew size }\end{array}$ & $\mathbf{3}$ & $\mathbf{5}$ & $\mathbf{3}$ & $\mathbf{4}$ \\
$\begin{array}{l}\text { Annual crew size reduction by } \\
\text { implementation of VT technol- }\end{array}$ & $\mathbf{0}$ & $\mathbf{4}$ & $\mathbf{0}$ & $\mathbf{2}$ \\
ogy & & & & \\
\hline
\end{tabular}

The first bold numbers are the total crew members that are required according to the current regulations. The second bold line deals with the possible crew reduction if the VT technology is applied

Both these have nearly identical minimum crew requirement and classify the vessel operations into the three operating regimes $\mathrm{A} 1, \mathrm{~A} 2$ and $\mathrm{B}$. The minimum crew requirements for the two extreme sailing regimes and for two different vessel classes are summarised in Table 1. When comparing the minimum crew requirements at the two operating regimes and it is considered that two crew rotations work on a continuously operating vessel, a reduction of up to four crew members can be achieved by moving the crew requirements from a $B$ regime to an A1 (Fig. 1).

One final crew-related difference that the two regions present is the type of employee. On small family-owned vessels, most of the employees are family members. At times, an external crew member is hired to allow operation at an enhanced operating regime. On the Danube, the employees tend to be mobile workers, whose stay on the vessel is temporary. In either case, there currently is a shortage of skilled workers on inland vessels [5]. On the Rhine the average age of qualified captains is rising, causing a lack of young, highly skilled boat masters that could take over small family businesses [18]. While on the Danube, the mobile workforce increasingly leaves for employment in the Rhine region to obtain higher wages [19].

The personnel cost in countries along the Rhine are similar and lie, on average, around $€ 40.000$ per person per year. The personnel costs from Danube countries are approximately $80 \%$ lower, with an average of around $€ 8.000$ per person per year, as illustrated in Fig. 2. The here provided annual cost per person are averages across all roles. The crew cost can sgnificantly vary between roles, which has an effect on the VT savings. More detail of the cost of specific crew roles is provided in Sect. 4.4. 


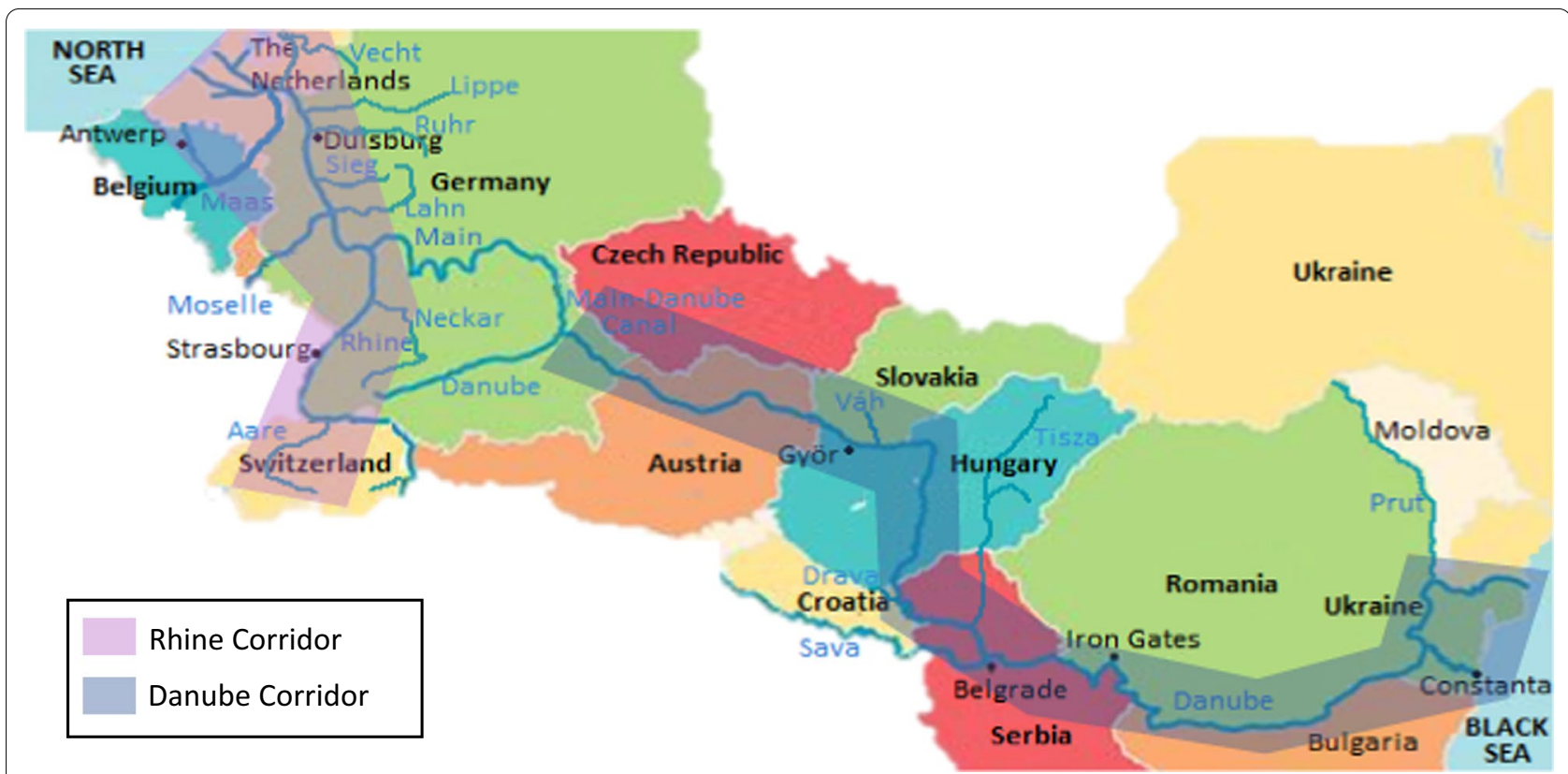

Fig. 1 Map of the Rhine and Danube corridors

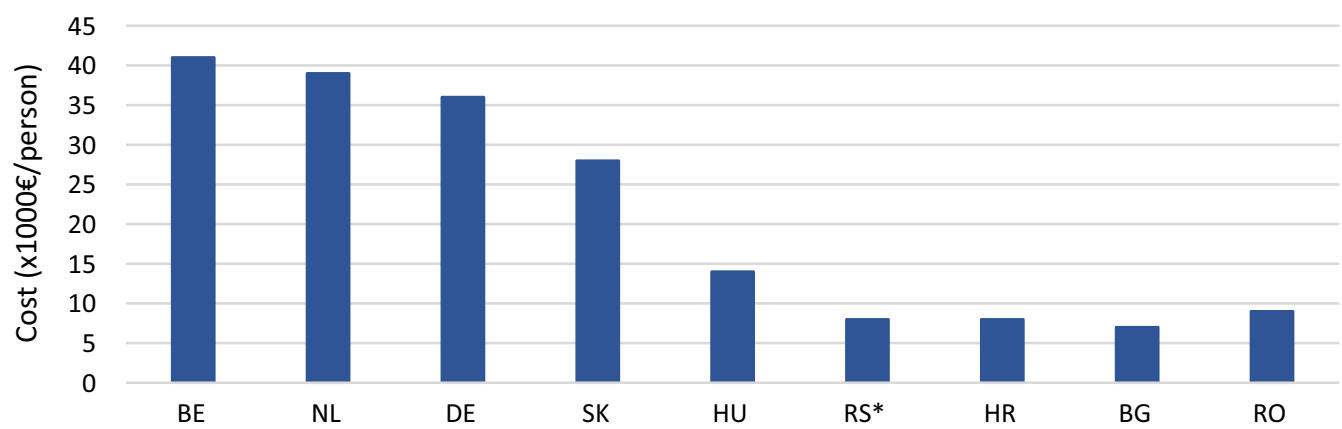

Fig. 2 Average annual personnel cost per person (2016). Source: (1) CCNR, 2019 (2) *statistical Office of the Republic of Serbia 2019

Table 2 Quantity of goods transported (× 1000 t)

\begin{tabular}{lll}
\hline Countries & Import/export & National \\
\hline RO & 10,399 & 14,697 \\
BG & 2876 & 1695 \\
RS & 6128 & 862 \\
HR & 453 & 0 \\
HU & 2072 & 200 \\
SK & 1879 & 36 \\
AT & 6276 & 609 \\
\hline
\end{tabular}

Source Danube Commission (2017)

\subsubsection{Cargo volume and fleet composition}

Another difference between the Rhine and the Danube corridor is the cargo volume, which also dictates the number of vessels used. The Rhine has by far the largest

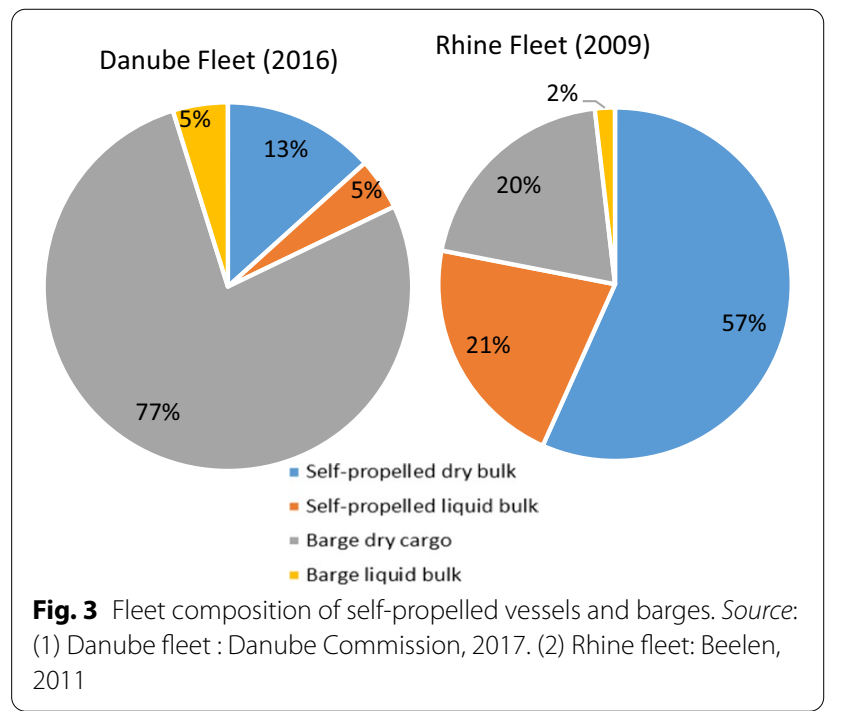


cargo volume transported along its length with about 186 million tons in 2017. Only about $10 \%$ of the European inland waterway transport, 39 million tons (2017), goes via the Danube [18].

The flows of goods on the Rhine are both regional and international. On the Danube however, most of the goods are moved internationally up the river. As can be seen from Table 2, only Romania makes significant use of the river to move goods nationally.

The development of the VT concept currently targets only self-propelled vessels, even though a large number of inland vessels are barge convoys. ${ }^{1}$

The active fleet size on a corridor can be estimated using the records of numbers of ships entering ports and locks [18]. The Danube fleet is estimated to be composed of approximately 2700 vessels and barges [17]. In contrast, the Rhine fleet is composed of about 8200 vessels and barges [4]. Figure 3 emphasizes the distribution of the difference in the types of vessels used. The large operators on the Danube mainly ship dry bulk on long-term contracts and often make use of barge convoys. Smaller companies are left serving the niche markets and shortterm contracts [40]. Only around 480 vessels, $18 \%$ of the fleet, are self-propelled. This share gradually increases as the barges get decommissioned and are replaced by second hand self-propelled Rhine vessels [3].

The Rhine fleet composition contrasts that of the Danube, as there about $78 \%$ of the vessels are self-propelled, 6400 vessels [4]. Additionally, the liquid cargo market is significantly larger. The 17 million tonnes of container goods moved in 2017 make up a fairly small segment of the market, however one that holds a lot of potential to be able to compete with other modes of transport [9]. Nearly all container transport is performed on the Rhine; the Danube region has very little waterborne container transport.

\subsection{Corridor differences of other influence factors 2.2.1 Geographical and environmental}

Differences in nautical standards in the respective corridors have had an effect on waterborne transportation efficiency. The Rhine has been a regulated waterway for a long time, ensuring it meets the needs of the IWT sector. It has only been in recent years that investment has been pushed into the Danube region so that it can comply with 2013 regulations on aspects such as waterway dimensions, minimum draught and bridge height requirements. This compliance is, however, not expected to be met until 2030 [21].

${ }^{1}$ Barge convoys are more challenging to be under control of another vesse and is hence kept for later stages of the concept's implementation.
2.2.1.1 River dimensions and tributaries The Danube has $2415 \mathrm{~km}$ of navigable length and it is 2.7 times longer than the navigable stretch of the Rhine that spans over $885 \mathrm{~km}$. The mean transport distance of goods on the Danube is $600 \mathrm{~km}$, whereas that on the Rhine is only about $200 \mathrm{~km}$ [49]. The Rhine has many river tributaries, such as the Aare, the Main or the Mosel (Fig. 1) and its estuary spreads through the entirety of the Netherlands, linking to a great number of canals. All these waterways run through a densely populated (average 250 people/ $\mathrm{km}^{2}$ ) region of Europe. These conditions make it possible for cargo to reach economically relevant locations and even facilitate door-to-door delivery for some industrial plants in Belgium and the Netherlands [39].

The situation on the Danube differs; while the main river arm transports large quantities of goods, there are only a few tributaries of the river. ${ }^{2}$ The average population density around the Danube lies at 140 people $/ \mathrm{km}^{2}$ [39], therefore; confining the transport access to specific regional areas and relying on extensive pre and end-haulage by road to get goods to a variety of locations [49].

Even though Danube has favourable VT condition due to its length, the tributaries of the Rhine contribute to a higher population density and thus also waterborne traffic density, which ultimately creates better VT implementation conditions on the Rhine.

2.2.1.2 Locks Locks are an essential infrastructure to allow navigation on the upper stretches of the rivers, but also a means to keep an overview of the fleet size and cargo volumes via the lock records. The Danube has 16 locks in the stretch up to Györ, Hungary. Most of them have standard European dimensions of $230 \mathrm{~m}$ by $24 \mathrm{~m}$, even though there are a few smaller ones upriver in Germany. On the central Danube, there are the power plant Iron Gate locks, between Serbia and Romania with dimensions of $310 \mathrm{~m}$ by $34 \mathrm{~m}$, after which the river flows freely into the Black Sea.

Seeing the cargo flows provided in Table 2, it can be expected that the VT route passes by at least the Iron Gates locks, since this allows the VT service to operate in the most traffic dense section of the Danube.

On the Rhine there are only ten locks with the last downstream lock located just after Strasbourg [8]. The lock chambers of new German locks are designed for large self-propelled vessels with width of $12.5 \mathrm{~m}$ [3], making them smaller than the ones that can be found on the central or lower Danube.
${ }^{2}$ Examples are Sava, the Tisa or the Prut but can only accommodate smaller vessel classes. 


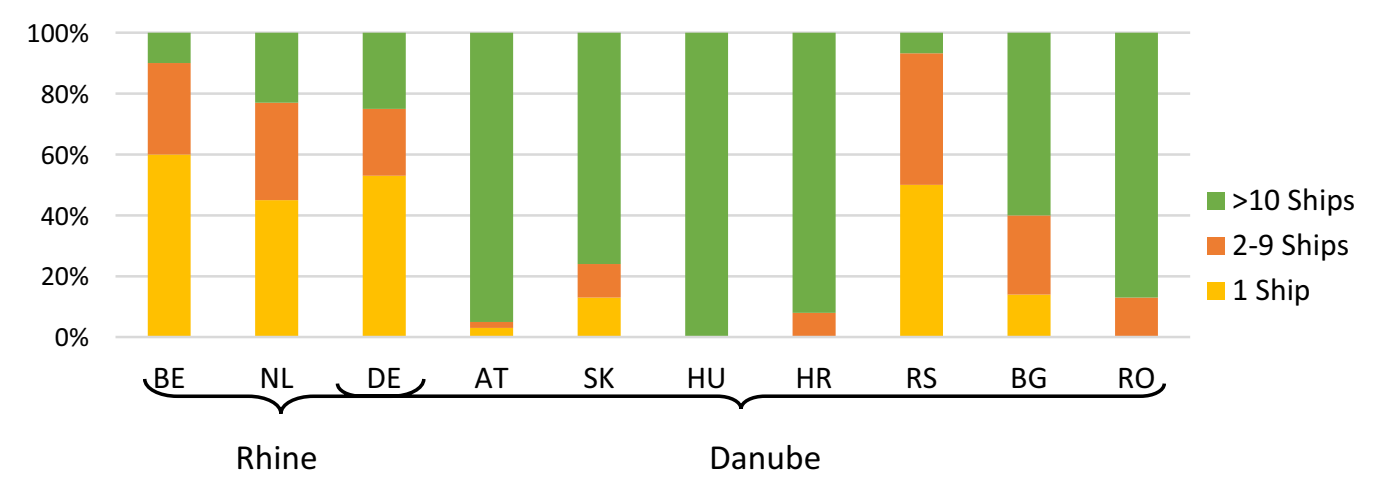

Fig. 4 Inland ship owners expressed by the number of ships owned. Source: authors adaptation of Eurostat [23] data, Maverick \& STC-Nestra [34] and Serbian Ministry of Construction Transport and Infrastructure [44]

This means VT passage on the main river Rhine and its tributaries can cause longer delays than is expected on the Danube lock passages, as more lock cycles are required to allow all the entire VT to pass.

\subsubsection{Environmental conditions At times of too high} water, ice or strong winds, the navigation on rivers can be suspended. Historical data shows that the average days of navigation suspension are around $5-6 \%$ of the annual days on both rivers $[9,49]$.

Low water will cause vessels to have restriction in draft and thus increase the cost per transport unit, as well as increasing the risk of ship-related accidents due to grounding. There are no official guidelines for ship operators on how to deal with low water situations; it is thus dependent on the individual vessel operators to decide whether to keep operations running in these situations [36]. The lack of minimum water depth of $2.5 \mathrm{~m}$ along the length of the Danube means that low water can cause major navigational bottlenecks, whereas the Rhine often has a depth of $3.5 \mathrm{~m}$ which helps improve the conditions [42].

\subsubsection{Geo-economic conditions}

2.2.2.1 Business structure The business structure on the Danube allows for multiple VT business models (BMs) to be considered. On the Rhine, a large part of the fleet is composed of small family businesses. In contrast, on the Danube, most vessels are owned by fairly big, former state-owned companies [47]. Figure 4 quantifies the extent of this difference for the available Eurostat data between the 2003 and 2012 time frame [23, 34]. While in Belgium, the Netherlands and Germany, companies that own more than ten vessels makeup at most $25 \%$ of the fleet, in most Danube countries, such companies own $60 \%$ to $100 \%$ of the fleet. The only Danube country that has similar vessel ownership to what can be found on the Rhine, is Serbia.
The business structure on the Danube allows for multiple VT BMs to be considered. There, individual companies or alliances of only a few partners can consider setting up the VT for their own operations. On the Rhine, however, the BM is mainly limited to a platform-based model where many individual businesses join the services of a third party organizer.

2.2.2.2 Vessel types European vessels are classified by CEMT classes. The self-propelled vessel sizes sailing on a regional level are typically CEMT class I-III, whereas internationally operating vessels are typically classes IV and above. On the Rhine the most common vessels are equivalent to the dimensions of CEMT class IV and V [40].

As mentioned in Sect. 2.1.2, there are many barge convoys of CEMT class VI and VII sailing on the lower Danube. Self-propelled vessels are of similar size to their most popular counterparts on the Rhine as some of the larger ones are former Rhine vessels that have been repurposed for use on the Danube [49], even though they are not the most effective vessel designs for the shallower water conditions on the Danube [3]. The shallower waters and less variable conditions on the Danube lead to lower speeds.

2.2.2.3 Ports and transshipment equipment On the Danube most ports are well equipped for transhipment, with 40 inland E-ports, which are ports of international significance. The average distance between these ports is $60 \mathrm{~km}$, while the E-Ports on the Rhine are on average only $20 \mathrm{~km}$ apart [26].

An investigation from PINE [39] estimated the Rhine ports to be 2.5 times more effective than the Danube ones, even though the crane density is higher on the Danube [39]. Yet, on the Rhine the higher traffic density causes congestions that adds significantly to the port waiting times. While no official figure is available, interviews 
with a Danube ship operator revealed that the waiting times on the Danube are comparable to those experienced on the Rhine. Therefore, these port waiting times are set to be equivalent in the further assessment of this article.

\section{VT assessment methododology}

Now that the influence factors have been identified and discussed, the VT concept's viability can be assessed using a quantitative model. The aim of the VT assessment model is to determine the economic viability of the VT concept. This is achieved when:

1. the transport cost of the VT user is equal to or lower than that of the current reference vessels;

2. the net savings of the FVs (i.e. the maximum combined subscription fees of all participants) at least cover the VT operator costs created by providing the leading service;

3. the number of participants that are in the VT at any given time does not surpass feasible conditions of what the corridor can accommodate

When identifying the needs for a successful implementation two aspects are considered:

1. boundary conditions, which are fixed by the environment or by economical regional setting

2. viability requirements, which are influenced by boundary conditions but also operational choices of the VT operator, such as operating, speed route length or departure intervals.

The cost model developed for this article allows the identification of the VT feasibility checks. These allow the study of the effects of varying operating conditions and evolving boundary requirements on the VT viability requirements. The three feasibility checks focused upon in this paper are:

1) Minimum number of FVs per VT,

2) Minimum distance that FVs spend in VT,

3) Minimum required fleet shares.

The developed model assesses the viability of the concept by comparing the annual cost per transported ton of a reference vessel that sails individually to a vessel that sails as a part of a VT on the same route. This section provides a fundamental understanding of the methodology and its sources. ${ }^{3}$

\footnotetext{
${ }^{3}$ A detailed description and overview of the equations is provided in the annex of this paper.
}

The approach to calculating the VT viability is based on a previous model which was presented in detail in Colling and Hekkenberg $[15,16]$. For the purpose of this research this model has been enriched with the following additions: (1) lock passage delays and navigation day suspension are now included in the calculations. (2) Data from the case studies, identified in Sect. 4, are used to determine the number of return trips and hence the amount of cargo moved annually, i.e. the productivity. (3)This is now calculated for both the reference vessel and the FV conditions. The maximum FV cost is determined based on the productivity ratios between the reference and the $\mathrm{FV}$, and the reference vessel cost, to ensure that the VT operating conditions are at least equivalent to the reference vessels.

With the updated assessment model the following research approach is used in this paper:

1. The calculation of the VT viability based on the corridor features identified in Sect. 2 and applied in the model described in this section.

2. A sensitivity analysis that studies the effects of variations in the main influencing factors on the applicability of the VT in both the Rhine and Danube region.

3. A feasibility check to see if the VT can be implemented in both the Rhine and Danube region.

With the updated model and this approach it is possible to assess if it possible to apply the VT concept in both the Rhine and Danube region.

\section{Application cases}

This section gathers the information presented in Sect. 2 and introduces the input data for the Danube and Rhine corridor case. It summarizes all input parameters used to in the VT assessment model of these two cases, presents and explains the variations that are performed in the sensitivity analysis.

The parameters that are a reflection of for the Rhine and the Danube corridor features are presented in Table 3. Many of the parameter values are based on the description and references provided in Sect. 3, however, some require more detailed explanation.

\subsection{Route length}

With the Danube having a mean transport distance that is three times as large as that on the Rhine, it is deemed most representative for the respective corridors to operate the VT over a shorter route along the Rhine than along the Danube. The Danube case LV route length of $878 \mathrm{~km}$ is comparable to a distance between Belgrade and Cernavoda, which is the point at which the DanubeBlack sea canal begins (see Fig. 1). This distance reflects the length of the lower Danube that has the least number 
Table 3 Input data for corridor cases

\begin{tabular}{lll}
\hline Parameters & Danube & Rhine \\
\hline LV routes length & $878 \mathrm{~km}$ & $325 \mathrm{~km}$ \\
Number of locks & 2 & 0 \\
VT operator & Single company & Third party (platform based) \\
VT user & Single company & Small-family businesses \\
FV port times & $58 \mathrm{~h}$ (Class V), 54 h (Class IV) & $58 \mathrm{~h}$ (Class V), $54 \mathrm{~h}$ (Class IV) \\
LV port time & $10 \mathrm{~h}$ & $10 \mathrm{~h}$ \\
FVs types & CEMT Class V, IV & CEMT Class V, IV \\
Current & $4 \mathrm{~km} / \mathrm{h}$ & $4 \mathrm{~km} / \mathrm{h}$ \\
Reference vessel operating regime & $\mathrm{B}$ & $\mathrm{A} 1 / \mathrm{A} 2 \mathrm{or} \mathrm{B}$ \\
Crew cost savings & $€ 75.500$ (Class V) and $€ 65.000$ (Class IV) & $€ 389.100$ (Class V) and $€$ \\
Fleet size & 480 & 293.600 (Class IV) \\
Departure interval & $24 \mathrm{~h}$ & 6400 \\
Number of LV & 6 & $6 \mathrm{~h}$ \\
VT operating speed of VT & $15.5 \mathrm{~km} / \mathrm{h}$ & 10
\end{tabular}

Table 4 Vessel properties

\begin{tabular}{lll}
\hline Vessel properties & \multicolumn{2}{l}{ Vessel type } \\
\cline { 2 - 3 } & V & IV \\
\hline Length $(\mathrm{m})$ & 110 & 81 \\
Beam $(\mathrm{m})$ & 11.4 & 9.5 \\
Installed power $(\mathrm{kW})$ & 1071 & 1063 \\
SFC $(\mathrm{g} / \mathrm{kWh})$ & 210 & 218 \\
Capacity $(\mathrm{t})$ & 2200 & 1500 \\
Operating speed Rhine $(\mathrm{km} / \mathrm{h})$ & 18 & 18 \\
Operating speed Danube $(\mathrm{km} / \mathrm{h})$ & 15.5 & 15.5 \\
Capital cost $($ million $€)$ & 2.46 & 1.80 \\
\hline
\end{tabular}

of bottlenecks along the way. The $325 \mathrm{~km}$ route length on the Rhine is equivalent to the distance between Antwerp and Duisburg. In both case studies, the FVs are able to continue their journey alone once the VT has reached its destination, albeit only with an A1 operating regime due to the reduced crew size.

\subsection{VT business models}

As was demonstrated in Sect. 2.2.2, the operators of the VT will have different BMs in the respective corridors. On the Danube corridor, this means that the savings are the benefits for the VT operator, which for a large company can be summed up over the entire fleet.

The third party business model that is applied on the Rhine corridor assumes the VT coordinator to be the LV operator. It additionally requires platform cost which are evenly distributed over the number of LVs in the transport system and will therefore be paid as part of the FV
Table 5 Vessel cost elements

\begin{tabular}{lll}
\hline Input items & Vessel & VT control system \\
\hline Interest & $5 \%$ & $5 \%$ \\
Depreciation & Over 20 years (5\%) & Over 5 years (20\%) \\
Insurance & $0.75 \%$ & $0.75 \%$ \\
Administration & $2.5 \%$ & $2.5 \%$ \\
Maintenance & $0.8 \%$ & $2 \%$ \\
\hline
\end{tabular}

contribution fee. More details on the calculation differences can be bound in the "Appendix".

\subsection{Vessel types}

The dimension of the self-propelled vessels used, stay the same no matter the corridor application. A difference in operating speed of different vessels classes is however set, as the on average shallower water on the Danube does not allow vessels to sail as fast as in the deeper waters on the Rhine. BAW [3] suggest the operating speed differences to be between $15 \mathrm{~km} / \mathrm{h}$ and $18 \mathrm{~km} / \mathrm{h}$. It should be noted that the VT speeds are adapted such that they fit the return trips and the departure intervals of the respective case, without causing any waiting times for the LV. The Danube case thus has a VT speed of $15.5 \mathrm{~km} / \mathrm{h}$, which is the operating speed of the vessels, while in the Rhine case the VT speed is $17.2 \mathrm{~km} / \mathrm{h}$, slightly lower than the expected operating speed.

Table 4 summarizes the vessel properties used for the cased. Table 5 provides the cost information needed to determine all different vessel cost presented in the methodology for both the vessels and the VT control system. 
Table 6 Annual wage of inland crew per role

\begin{tabular}{|c|c|c|c|c|c|c|}
\hline \multirow[t]{2}{*}{ Role } & \multicolumn{3}{|c|}{ Boat master } & \multirow[t]{2}{*}{ Helmsman } & \multirow[t]{2}{*}{ Boatman } & \multirow[t]{2}{*}{ Apprentice } \\
\hline & $>86 \mathrm{~m}$ & $70-85 \mathrm{~m}$ & $<70 \mathrm{~m}$ & & & \\
\hline Dutch & $€ 56.300$ & $€ 55.100$ & $€ 54.100$ & $€ 46.000$ & $€ 31.800$ & $€ 40.300$ \\
\hline Serbian & $€ 17.600$ & $€ 16.200$ & $€ 14.800$ & $€ 9.500$ & $€ 8.800$ & $€ 7.500$ \\
\hline
\end{tabular}

Table 7 Sensitivity analysis input data

\begin{tabular}{llll}
\hline Parameters studied & Base & Variations & II \\
\cline { 3 - 4 } & & $\mathbf{I}$ & $3.5 \mathrm{~m}$ \\
Water depth & $5 \mathrm{~m}$ & 22 days & 60 days \\
Navigation suspension & 18 days & $2(6.25 \mathrm{~h})$ & $8(7.07 \mathrm{~h})$ \\
Number of locks (departure interval) & $0(6 \mathrm{~h})$ & $30 \%$ & $60 \%$ \\
Percentage of Rhine crew income & $100 \%$ & $812 \mathrm{~km}(20 \mathrm{LVs})$ & $520 \mathrm{~km}(14 \mathrm{LVs})$ \\
Route length (number of LVs) & $325 \mathrm{~km} \mathrm{(10} \mathrm{LVs)}$ & $20 \mathrm{~h}(3 \mathrm{LVs})$ & $12 \mathrm{~h}(5 \mathrm{LVs})$ \\
Departure intervals (number of LVs) & $6 \mathrm{~h}(10 \mathrm{LVs})$ & & \\
\hline
\end{tabular}

The VT control system annual cost sums up to $€ 24.200$. The only cost estimation of this input data does not include is the crew cost, which is covered in detail in the next sub-section.

\subsection{Crew cost}

Crew cost are difficult to come by, but for the Rhine navigation, acceptable cost estimates can be made through guiding wage-tables; to the best of knowledge of the authors these do not exist in the Danube countries. This article makes use of Dutch wages from which the relevant roles have been presented in Table 6 [41]. This is compared to the Serbian wages for the Danube countries. Interviews with Serbian ship operators allowed rough estimates to be set. ${ }^{4}$ The conversion of these monthly wages into the annual cost presented in Table 6 assumes an indirect crew cost and employment related cost 30\% [24] for both the Dutch and the Serbian crew cost. These cost are considered to be inclusive of all relevant crew related cost (overhead, etc.). In Serbia, the crew receives additional bonuses such as $25 €$ per day for international travel, which are added to the base salary. This can make up a substantial part of the salary considering that if the vessel spends a third of its time abroad, the crew member each receive about $2.700 €$ bonus per year. It is assumed that this bonus is paid for one-third of the operating time, given that the Danube route runs two-thirds of its

\footnotetext{
${ }^{4}$ A captain's salary can range between $€ 700$ and $€ 870$ per month, lowestpaid sailor onboard earns $€ 280$ per month. The roles ranked in between are estimated according to these two extremes.
}

way through Romania and given that the vessel operates under a $B$ regime, thereby requiring two crews to rotate.

In order to judge the impact of the crew cost savings on the overall cost for operating an inland vessel, it is essential to know that crew cost can make up between $25 \%$ till $40 \%$ of the total cost for operating a class V dry cargo inland vessel $[1,4]$. Therefore the overall cost-saving potential is quite substantial.

\subsection{Departure interval}

Previous analysis of Colling et al. [16] has shown that a $6 \mathrm{~h}$ departure interval is an appropriate assumption for the Rhine case application. Given the longer route, the smaller fleet size and cargo volume on the Danube, presented in Sect. 2.1.2, this departure interval needs to be increased. Hence a departure interval of once per day is deemed appropriate for the Danube case to meet realistic participants requirements.

\subsection{Sensitivity study variations}

To demonstrate that the main factors as described in Sect. 2 are indeed the most influential, a sensitivity analysis is executed that includes the variation of some of the secondary influence factors as well. The analysis uses the Rhine case parameters as a base scenario for variation. The results are provided for class $\mathrm{V}$ vessel compared to a $B$ operating regime of the reference vessels.

Six factors are varied. A summary of all these factors variations is presented in Table 7 . Every factor variation ' $\mathrm{I}$ ' is representative of the Danube case values. The variation 'II' is adding another extreme case for the navigation suspension variations and intermediary reference points 


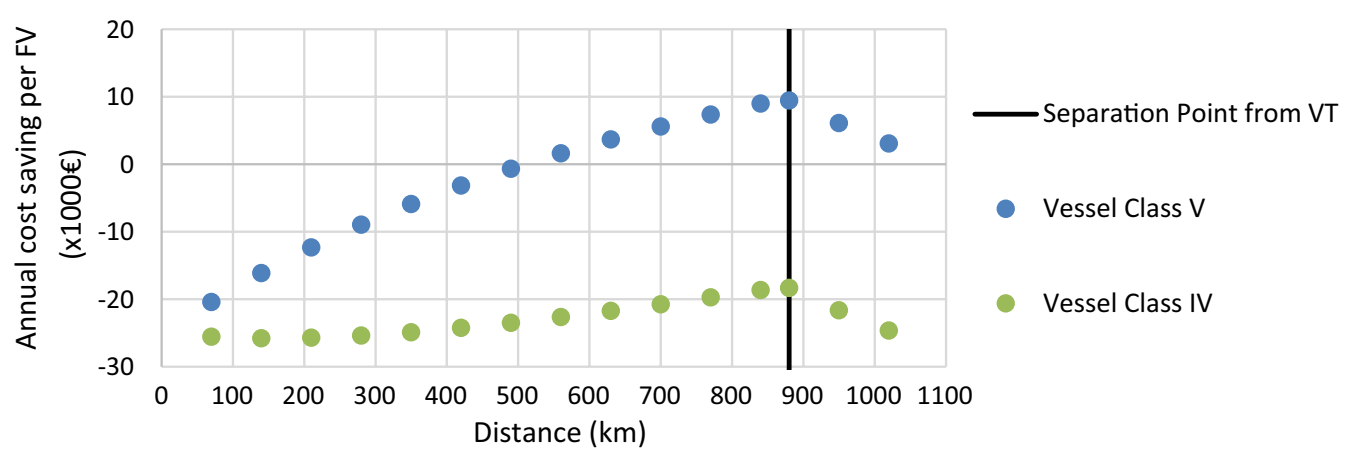

Fig. 5 Annual cost savings per FV for the Danube vessel class IV and V
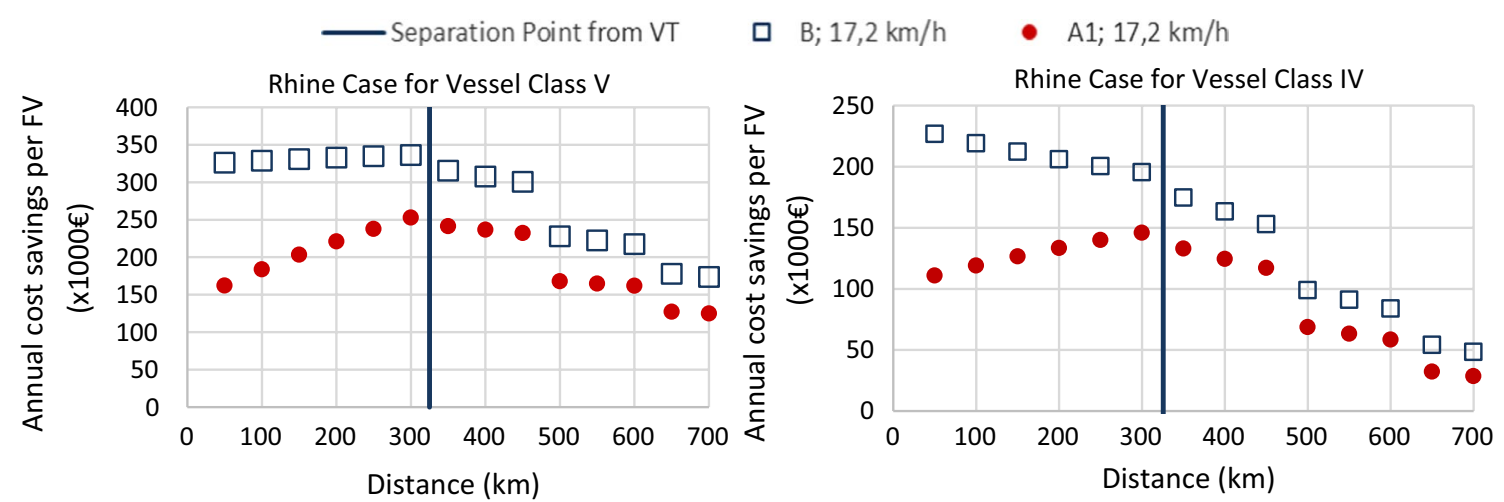

Fig. 6 Annual cost savings per FV for the Rhine case

between the Rhine and the Danube case for all other parameters. The values in the brackets indicate the values that change together with the parameter variation. For the lock passage, the departure interval is slightly adapted to avoid waiting times for the $\mathrm{LV}$, whereas variation in the route length and the departure interval causes changes in the required number of LVs.

\section{Results}

\subsection{Base case results}

Figure 5 and the plots in Fig. 6 summarize the annual cost savings changes for the Danube and the Rhine corridor. The vertical line on the plots denote the separation point from the VT, which means that beyond this point, FVs sail under their own navigational control in an A1 regime. This explains the decrease in savings per FV, once the separation point is passed, as the resting times are again included, reducing the productivity of the vessels compared to the continuous operations in the VT.

With the limiting conditions set in the previous section, the Danube case only shows to be viable if a class V FV stays part of the VT for more than $500 \mathrm{~km}$ (Fig. 5). A maximum of $€ 10.000$ cost savings can be achieved by a class $\mathrm{V}$ vessel. The long departure interval combined with the small crew cost-benefit and the reduction in productivity compared to the $B$ reference vessel regime is in most cases not able to create sufficient benefits to outweigh the VT system cost.

The Rhine corridor results in Fig. 6 provided for a comparison to the $\mathrm{B}$ and the $\mathrm{A} 1$ operating regime, as the smaller single vessel companies are more likely to currently be operating at the $\mathrm{A} 1$ regime. A clear difference between the $\mathrm{B}$ regime and the $\mathrm{A} 1$ regime can be seen while sailing in the VT. Similarly to the observations in the Danube case, the class V vessels are able to better compensate for the loss of productivity compared to the $\mathrm{B}$ regime, than class IV vessels. For the A1 regimes, the productivities of the vessels improve as the distance increases, as the vessels can make use of sailing past the operating restrictions. This productivity peaks until the FV leaves the VT. This explains why the B and A1 regime lines diverge so much at short distances. At the short distances, the FVs compared to the A1 regime are not able to have much productivity gain, whereas the FV compared to the B regime have crew cost savings no matter the distance spent on the VT. 
Table 8 Average change in cost savings due to the variation of influence parameters

\begin{tabular}{|c|c|c|c|c|c|c|c|c|c|c|c|}
\hline \multirow{2}{*}{$\begin{array}{l}\text { Influence factors } \\
\text { Variations }\end{array}$} & \multirow{2}{*}{$\begin{array}{l}\text { Water depth }(\mathrm{m}) \\
-1.5\end{array}$} & \multicolumn{2}{|c|}{$\begin{array}{l}\text { Days of navigation } \\
\text { suspension }\end{array}$} & \multicolumn{2}{|c|}{ Lock passage } & \multicolumn{2}{|c|}{ Rhine income (\%) } & \multicolumn{2}{|c|}{$\begin{array}{l}\text { VT route } \\
\text { length }(\mathbf{k m})\end{array}$} & \multicolumn{2}{|c|}{$\begin{array}{l}\text { Departure } \\
\text { intervals (h) }\end{array}$} \\
\hline & & 22 & 60 & 2 & 8 & $60 \%$ & $30 \%$ & 52 & 812 & 12 & 20 \\
\hline Iange III savings & $-2.3 \%$ & $-1.1 \%$ & $-3.1 \%$ & $-6.2 \%$ & $-24.7 \%$ & $-48 \%$ & $-84 \%$ & $51 \%$ & $56 \%$ & $-8.8 \%$ & -15 \\
\hline
\end{tabular}

Figure 6 makes it clear that once the FV leaves the VT, the savings show sudden decreases every $180 \mathrm{~km}$. This is the distance a FV sail in a daily sailing regime. The drop is representative of the large resting time.

The most important point to note is that all conditions show positive savings and therefore demonstrate viability. The annual cost savings reaching up to $€ 389.100$ show that the Rhine case is able to achieve much more secure benefits given the uncertainty in the input data. These numbers demonstrate that already the combined maximum savings of two FVs, whose reference conditions operate at a $\mathrm{B}$ regime, would be able to compensate for the $€ 422.500 \mathrm{VT}$ operator cost created. Hence, for the Rhine VTs only require one FV per operating LV.

\subsection{Sensitivity study}

A sensitivity analysis has been added to the analysis of the results how they are impacted if different case study input parameters are used. The results are expressed in terms of percentage change of the annual cost savings compared to the Rhine base case per vessel. For all but the lock passage variation, the changes are provided at the point of maximum savings, when the FV spends the entire trip as part of the train i.e. at $325 \mathrm{~km}$. The results are summarized in Table 8 .

Looking at the results of all parameter variations of Table 8 , the variation of the water depth and the days of navigation suspension have a negative effect on the FV savings achieved per tkm. Even though the $1.5 \mathrm{~m}$ decrease of water depth causes $2.3 \%$ decrease in savings, due to higher fuel consumption, this depth variation is not going to decrease much more as then vessels can no longer navigate on the river. This is why the navigation day suspension has a lot more potential to reduce the productivity and FV savings of vessels than purely shallower waters does. It needs to be considered that the unreliability these two factors create, has a negative effect on cargo owners willingness to choose waterborne transport. If the waterborne conditions become too unreliable, the customer are likely to change their choice of transport mode and will not return. Hence, while the results in Table 8 show a small effect, these long term and demandside effects are not reflected in these results.
The lock passage sensitivity analysis results need to be viewed similarly. The Rhine case has shown that a VT can be composed of as little as one FV. This would mean the entire VT fits into a single lock cycle. For such short trains the only difference between the VT and current operating conditions are the VT waiting times. The sensitivity analysis for the 2 and 8 lock passages allows to conclude that every added lock reduces the FV savings per tkm by $3.1 \%$. Apart from the additional number of lock cycles that could be required if the VT becomes too long, the VT is also affected by locks that are located in close proximity to each other. The VT aims to reduce the workload of the crew on the FVs; yet if every few hours the crew is called onto the bridge to take over a lock manoeuvre the benefit for the VT user diminishes. Therefore the VT operators should choose routes that have either very clustered or very few widely spread locks along the route.

The changes in departure intervals cause at most a variation of about $€ 60.000$ of saving (i.e. 19\%) and the increase in sailing distance improves the average savings by up to $56 \%$. The income variation has the largest effect on savings. A decrease of as large as $84 \%$ (i.e. $€ 270.000$ ) is experienced when the income is lowered to an equivalent income level to that on the Danube. This large reduction of benefits can have an effect on the number of FV needed in a VT, as the savings drop below the LV cost threshold of $€ 24.200$.

\subsection{Feasibility checks}

The feasibility checks identify the minimum distance a FV has to stay in the VT, the minimum number of FVs per LV, the number of participants required in the transport system and the market share required of the existing self-propelled fleet. All but the minimum distance feasibility checks are provided at the VT trip length, so assuming the FV stays sailing in for the entire trip.

The feasibility checks of the Rhine case and an adjusted Danube case results are summarized in Table 9. The adjusted Danube case has increased the trip distance to Budapest which is thus overall $1400 \mathrm{~km}$, a reduced departure interval of every $6 \mathrm{~h}$ and a crew cost estimation that is about $20 \%$ higher than the 
Table 9 Feasibility checks for the Rhine and the Danube cases

\begin{tabular}{|c|c|c|c|c|c|}
\hline \multirow[t]{2}{*}{ Case } & \multirow[t]{2}{*}{ Vessel type } & \multicolumn{4}{|l|}{ Feasibility checks } \\
\hline & & FV distance spent in VT & Number of FV per VT & $\begin{array}{l}\text { Number of } \\
\text { participants }\end{array}$ & Fleet share (\%) \\
\hline \multirow[t]{2}{*}{ Rhine } & V & No min distance & 1 & 20 & $<1$ \\
\hline & IV & No min distance & 1 & 20 & $<1$ \\
\hline \multirow[t]{3}{*}{ Danube } & V & No min distance & 1 & 36 & 8 \\
\hline & IV & No min distance & 2 & 54 & 11 \\
\hline & Combined & No min distance & 1 & 36 & 8 \\
\hline
\end{tabular}

originally used values. These adjustments allow also class IV vessel to achieve viable conditions. All scenarios do not require a minimum distance for the FV to stay as part of the train. Even with the higher VT platform cost, the Rhine conditions show a smaller than $1 \%$ fleet share requirement of the self-propelled vessel fleet, which is realistically achievable.

On the Danube, the VT operating cost are a lot lower, but the required fleet share rises up to $11 \%$ of the self-propelled vessel fleet. While this appears high, due to the larger businesses on the Danube, this can be feasible since it can represent one large company or an alliance of a few operators working together to improve their productivities.

Seeing that the departure intervals make such a large difference, one could consider that further benefits can be achieved if the BM is changed to a departure on-demand basis. Such a BM would require detailed knowledge of all departures and destinations as well as excellent coordination of vessels.

\section{Conclusion and discussion}

This article presents a comparison of the geographical and geo-economic features of the Rhine and the Danube inland navigation corridors in light of the potentials for the introduction of the VT concept. It describes impact factors that have an effect on the VT concept implementation and assesses the viability for both operating corridors. While the Danube has the advantageous conditions that it is long and has larger cooperation running the waterborne transportation sector corridors, the Rhine provides favourable conditions in terms of crew income levels and waterborne traffic density. These latter two are the main influence factors for the VT implementation.

The case studies showed that the Rhine case has the potential, from a transport cost point of view, to support a viable application of the VT concept. A reduction in transport cost, as determined in the analysis, for IWT would make this form of transport more attractive, but also other factors, such as the further integration of the
VT in the overall supply chain, play a role in the successful implementation of this IWT transport concept.

With respect to the Danube case, more careful consideration of its applicability is needed. Even if the benefits can be increased through a potential increase in crew income, the traffic density on the Danube is likely not to be high enough to implement the concept. A way in which the traffic density can be increased is by adding push convoys into the train, as they are more numerous on the Danube than self-propelled vessels.

One point for further research is to research how these cargo volumes could be attracted by the VT concept or by integration push barge operations into the VT on the Danube. Next to that, also the main IWT sector-related barriers, as mentioned in Sect. 2, need to be addressed and further researched. Additionally, this article mainly focused on the application of the VT concept within European waterways, yet the insights gained make it possible to extrapolate the application of the concept onto different rivers around the world. Further investigation could be looking at for instance, the Yangtze River that is pushing to develop and has larger traffic densities along its length.

\section{Appendix}

\section{Nomenclature}

A1 Operating regime that allow $14 \mathrm{~h}$ operations

B Operating regime that allows continuous operations

$C_{f e e} \quad$ Annual VT contribution fee cost ( $€ /$ year)

$C_{L V} \quad$ Annual LV cost created by providing the leading service (€/year)

$C_{V T} \quad$ Annual VT technology cost ( $€ /$ year)

$\mathrm{D} \quad$ Annual number of operating days ( $€ /$ year)

d VT trip distance $(\mathrm{km})$

$d_{\text {in }} \quad$ Distance of the FV spent in the VT $(\mathrm{km})$

FV Follower Vessel

i Original sailing regime of the reference vessel 
LV Lead vessel

$n_{F V} \quad$ Required number of FVs per LV

$n_{L V} \quad$ Number of LV in the transport system

$r \quad$ Number of crew member roles

$\mathrm{T} \quad$ Annual operating hours (h/year)

TSC Transition Stage Case

$t_{p} \quad$ Time spent in port (h)

$t_{r} \quad$ Time spent resting (h)

V Cargo capacity of the vessel ( $\mathrm{t}$ )

$v_{c} \quad$ Speed of river current $(\mathrm{km} / \mathrm{h})$

$v_{V T} \quad$ Operating speed of VT $(\mathrm{km} / \mathrm{h})$

$\Delta_{\text {fuel }} \quad$ Change in annual fuel cost $(€)$

A2 Operating regime that allow $18 \mathrm{~h}$ operations

$C_{F V} \quad$ Annual follower vessel cost (€/year)

$C_{R} \quad$ Annual reference vessel cost ( $€ /$ year $)$

$C_{i n t} \quad$ Bonus wage for every day spent sailing internationally (€/day)

$c_{w} \quad$ Annual crew wage ( $€ /$ year)

$d_{F V} \quad$ FV distance $(\mathrm{km})$ i.e. $d_{\text {out }}+d_{\text {in }}$

$d_{\text {out }}$ Distance the FV spends sailing on its own $(\mathrm{km})$

$d_{\text {int }} \quad$ Distance sailed internationally $(\mathrm{km})$

f Fleet size of single company

I Departure interval of the LVs (h)

M Fleet share

$n_{c} \quad$ Number of crew members

$\mathrm{P} \quad$ Annual productivity of a vessel ( $\mathrm{t} /$ year)

$p_{e x} \quad$ Percentage indirect and employment-related crew cost

$r_{r} \quad$ Number of crew member roles at reduced crew

$t_{l} \quad$ Time spent in lock passage (h)

$t_{t} \quad$ Return trip time (h)

$t_{w} \quad$ VT waiting time due to VT departure (h)

VT Vessel train

$v_{R} \quad$ Operating speed of the reference vessel $(\mathrm{km} / \mathrm{h})$

$\Delta_{\text {crew }}$ Change in annual crew cost $(€$ of participants. The information presented in this annex is based on the NOVIMAR deliverable by Hekkenberg and Colling $[15,29]$, with the addition of environmental factors of days of navigational suspension.

The calculation approach focuses on the calculation of the FV cost based on their relative productivity changes. All calculations are based on the cost calculation of a currently operating reference vessel and its refit counterpart operating as a follower vessel in a VT.

To start with, the VT operating speed is calculated using Eq. 1. The departure interval of the train is set within the assessment scenario in Sect. 5 of the main paper. The number of LVs in the transport system are determined such that the operating speeds of the VT are as close as possible to the operating speeds of the reference vessels.

$$
v_{V T}=\frac{d}{\operatorname{In}_{L V}-2 t_{p \& l}}+\sqrt{\frac{d^{2}}{\left(\operatorname{In}_{L V}-2 t_{p \& l}\right)^{2}}+v_{c}^{2}}
$$

Next, the return trip time is calculated. As can be seen from Eq. 2, the main difference between the reference vessel and the FV trip time the addition of the VT waiting time $\left(t_{w}\right)$, but also the fact that the section of the FV trip is calculated at the VT operating speed. As we are dealing with inland navigation, the vessel speeds are influenced by currents experienced on the river. The vessels are set to operate along the same route length all year. Hence, the length of this route, as well as the amount of time spent sailing, and resting per day are also taken into account for the trip time. Port times (including time spend on actions such as (un)loading, berthing, bunkering) also influence a return trip time but are not specific to VT operations. These port times are adjusted depending on the size of the vessel.

for reference vessel
This annex provides the detailed equations for both the Rhine and the Danube cases calculations. The assessment methodology for the single company and the subscription fee BM is for the most part identical. It differs mainly in the assumptions set for the determination of the number
Knowing the trip time allows the determination of the reference vessels productivity, at its original sailing regime and the productivity of FV at its VT conditions. The productivity is calculated using Eq. 3, for both the reference and FV conditions. Aside from the trip time 
Table 10 Number of crew and wages summary for the Rhine and Danube case

\begin{tabular}{|c|c|c|c|c|c|c|c|}
\hline \multirow[t]{3}{*}{ Role } & \multicolumn{4}{|c|}{ Number of crew } & \multicolumn{3}{|c|}{ Monthly crew wages } \\
\hline & \multicolumn{2}{|c|}{ Class V } & \multicolumn{2}{|c|}{ Class IV } & \multicolumn{2}{|l|}{ Rhine } & \multirow[t]{2}{*}{ Danube } \\
\hline & $\mathrm{A} 1$ & $\bar{B}$ & A1 & B & $\mathrm{A} 1$ & B & \\
\hline Boat master & 1 & 2 & 1 & 2 & $€ 2227$ & $€ 3185$ & $€ 680$ \\
\hline Helmsman & 1 & 1 & & & $€ 1829$ & $€ 2603$ & $€ 340$ \\
\hline Boatman & & 1 & 1 & 1 & $€ 1802$ & $€ 2577$ & $€ 280$ \\
\hline Apprentice* & 1 & 1 & 1 & 1 & $€ 1594$ & $€ 2279$ & $€ 280$ \\
\hline
\end{tabular}

* For the Danube case all apprentice positions are considered to be a boatman

the difference in computations between the two conditions lies in the annual number of operating hours (T). For the reference vessel, this is the operating hours given the original operating regime (i) minus days of no operations due to holidays $\left(r_{h}\right)$ or navigation restrictions due to water levels $\left(r_{w}\right)$. The number of operating hours for the $\mathrm{VT}$ is computed by considering both the time spent in and out of the VT, which allows operations either at a B or an A1 regime, as expressed in Eq. 4.

$$
P=\frac{24 T}{t_{t}} 2 V
$$

(i.e. antenna or distance sensors) on board of the vessels. This is estimated to be $€ 80,000$ by the developer Argonics Gmbh [2]. The insurance, interest, maintenance, administration and depreciation are calculated as a function of this investment cost. The depreciation time of this technology is five years.

If the VT is operated by a third party additional cost need to be considered apart from the VT control system cost. These cost are platform cost, that allow the coordination of the VT participants, which does not arise when the VT is operated by a single company. This cost includes software cost, but also shore-based

$$
\begin{aligned}
& \text { for } P_{R}: T=24 D_{i}-r_{w}-r_{h} \\
& \text { for } P_{F V}: T=T_{B+A 1}=24\left(\frac{d_{\text {in }}}{d_{F V}} * D_{B}+\frac{d_{\text {out }}}{d_{F V}} * D_{A 1}\right)-r_{w}-r_{h}
\end{aligned}
$$

Next, the CAPEX and OPEX of the vessel are determined as described in the main body of this paper. The OPEX costs of the reference vessel and the FV includes crew, fuel, maintenance, and administration cost, while the CAPEX costs are composed of depreciation, interest and insurance. The administration, as well as all CAPEX cost, are determined as a function of the newbuilding price of the vessel, which is a common approach that was adopted by for example Kretschmann et al. [32], Grønsedt [25], Lyridis et al. [33] or Verberght [47]. The new built price and maintenance estimation method for an inland vessel is taken from Hekkenberg [28].

The fuel costs are determined using Holtrop and Mennen [30] resistance prediction method, which has been adjusted to take shallow water effects into account according to the method proposed by Zeng et al. [50]. The specific fuel consumption is modelled as a function of engine loading and based on Caterpillar 3406E [6].

The VT control system cost and the LV cost calculations are based on the capital cost needed to get the installation of the VT track pilot soft- and hardware staff and offices. The platform cost assumptions are presented as part of the input data in the application cases.

The VT can create positive and negative effects on a vessels' productivity. The waiting times created before departure as well as the possible slowing down of the operating speed in the VT cause a negative effect on productivity. If compared to reference vessels that operate in a B regime, these negative products are a consequence of using the VT aside from the cost saving achieved by the crew cost saving. Compared to a reference vessel at an A1 regime, however, these negative effects on the FVs' productivity are largely outweighed by positive effects of sailing through the $10 \mathrm{~h}$ of resting period per day.

To ensure that the FV transport condition are at least equivalent to the reference operation, the FV cost is calculated based on the change in productivity and the reference vessels cost using Eqs. 5.

$$
C_{F V}=\frac{P_{F V}}{P_{R}} C_{R}
$$


Equation 6 allows to the net savings per vessel for the single company BM or the maximum contribution fee, a FV can pay to the LV to compensate for their service.

$$
C_{f e e}=S_{F V}=C_{F V}-C_{R}+\Delta_{\text {crew }}+\Delta_{f u e l}-C_{V T}
$$

The crew cost savings are determined based on the crew number and the crew wages summarized in the table below. As described in the main text, the crew numbers are taken from CCRN guidelines, and the UNECE Resolution No. $61[7,46]$. The crew wages for the Rhine case are from QUOVADIS [41] and those for the Danube are obtained from interviews with one of the largest shipping company along the Danube (they wish to stay anonymous so as not to disclose this comparative information to their competitors). On the Danube, a significant part of the wage is based on the number of days spent sailing internationally $\left(c_{\text {int }}\right)$, outside of their home country. This is not the case for the Rhine; hence there, it is set to 1 . The savings are calculated using the data in Table 10. These include the percentage indirect and employment-related cost $\left(p_{e x}\right)$ of $30 \%$ of the total wage [24]. These values are plugged into Eq. 7 to obtain the crew cost savings. The first sum in Eq. 7 determines the crew cost of the reference vessel for every crew role (r) at their original operating regime (i). The second sum calculates the cost of the FV operations with the reduced crew roles $\left(r_{r}\right)$ at an $\mathrm{A} 1$ operating regime. is operated and maintained by four shore-based workers with transport planning and IT skills. It is expected that each employee cost $€ 60.000$ annually, thereby summing up to a cost of $€ 240.000$ per year to cover the shore-based workforce. Finally, it also assumes that the VT operator makes a profit margin of $20 \%$ of the total cost. In the case, where the VT operator is an independent agent from the LV operators, additional margins need to be added. Given these additional cost assumptions and the 10 LVs operating on the Rhine VT transport system, the VT operator needs to gain a total of $€ 422.500$ ( $€ 42.250$ per LV) for its services to be economically viable. The calculations for this business model in this assessment are set such that the FV savings are the maximum contribution fee the VT operator can expect the FVs to pay for the service. This does not mean that the FV operators end up paying a subscription fee equivalent to their savings, as they also make financial benefits from joining the VT.

The main difference in the single company vs. third party business model lies in the calculations of the compensation cost for the service performed. The third-party business model needs the platform cost for coordination of the train to be included (i.e. licence, updates and shore-based personal) as well as a margin of profit. All these cost sum up to the VT operator cost and are evenly divided over the number of LV in the transport system, as indicated by Eq. 8 .

$$
\begin{aligned}
\Delta_{\text {crew }}= & \sum_{j=1}^{r}\left(n_{c, j}\left(c_{w, j}+\frac{c_{w, j} p_{e x}}{\left(1-p_{e x}\right)}\right)+n_{c, j} \frac{d_{\text {int }}}{d_{F V}} T_{i} c_{i n t}\right)_{i} \\
& -\sum_{j=1}^{r_{r}}\left(n_{c, j}\left(c_{w, j}+\frac{c_{w, j} p_{e x}}{\left(1-p_{e x}\right)}\right)+n_{c, j} \frac{d_{i n t}}{d_{F V}} T_{B+A 1} c_{i n t}\right)_{A 1}
\end{aligned}
$$

The change in fuel consumption $\left(\Delta_{\text {fuel }}\right)$ is the difference in the estimated fuel consumption between the two conditions, while the last cost component of Eq. 6, the VT cost, is composed of the VT control system cost. This VT cost is expected to be equivalent to the LV cost. The LV cost calculations are based on the capital cost needed to get the installation of the VT track pilot soft- and hardware (i.e. antenna or distance sensors) on board of the vessels. This is estimated to be $€ 80,000$ by the developer Argonics Gmbh [2]. The insurance, interest, maintenance, administration and depreciation are calculated as a function of this investment cost. The depreciation time of this technology is five years.

With respect to the third party service provider to manage the VT the following cost are determined. For the Rental of office spaces and software licences, updates and other overheads are estimate to be $€ 50.000$, where $€ 10.000$ is the expected annual fee for offices and screens in the remote control centre of the Port of Antwerp. The platform
The LV cost the single company needs to compensate for, is equal to the VT control system cost, as it is assumed that no waiting times are created for the LVs.

$$
C_{L V}=\left\{\begin{array}{lr}
\frac{\left(c_{V T} n_{L V}+c_{\text {platform }}\right)(1+p)}{n_{L V}} ; & \text { for platform based model } \\
c_{V T} ; & \text { for single company model }
\end{array}\right.
$$

Finding the number of required FV per VT is the point at which the cases differentiate dependenton the BMs. As shown in Eq. 9, the number of FV per VT for a subscriptionbased BM assumes the best-case scenario for the VT operator and the worse-case for the VT user, i.e. that the entire savings of the vessel operators are paid to the VT operator. For the single company use case, the cost savings generated need to outweigh the cost. Hence, the required FV participants indicate the minimum FVs required. Additionally, the benefits of one vessel type can help make the combined operations with another vessel type viable. 


$$
\mathrm{n}_{F V}= \begin{cases}\min _{C_{L V}} \sum_{j=x}^{n_{F V}} S_{F V, j} \geq C_{L V} \text { where } x=1 \ldots f ; & \text { for singlecompanymodel } \\ \frac{C_{L V}}{C_{f e e}} ; & \text { for plaformbasedmodel }\end{cases}
$$

In the case that $n_{F V}>L_{c}$ additional lock cycle time needs to be added to the original equations and a second iteration of the calculation method is calculated. As the case study results show, this is not needed, so the total number of participants is determined using Eq. 10.

$$
V T_{p}=n_{L V}+n_{L V} n_{F V}
$$

The final feasibility indicator of the fleet share is based on the fleet size of the self-propelled vessels identified in the main body of the paper and is calculated using Eq. 11.

$$
M=\frac{V T_{p}}{F_{s}} 100
$$

\begin{abstract}
Abbreviations
A1: Operating regime that allow $14 \mathrm{~h}$ operations; B: Operating regime that allows continuous operations; BG: Bulgaria; BM: Business model; CAPEX: Capital expenditure; DE: Germany; HU: Hungary; NL: The Netherlands; RS: Serbia; A2: Operating regime that allow 18 h operations; AT: Austria; BE: Belgium; CEMT: The classifications of European inland vessels; HR: Croatia; OPEX: Operating expenditure; RO: Romania; SK: Slovakia.
\end{abstract}

\section{Acknowledgements}

The research leading to these results has been conducted within the NOVIMAR project (NOVel Iwt and MARitime transport concepts) and received funding from the European Union Horizon 2020 Program under grant agreement $n^{\circ} 723009$. The authors also want to express their gratitude to the anonymous reviewers for their suggestions and comments to improve the quality of the paper.

\section{Authors' contributions}

The contributions of the authors are as follows: (1) AC wrote the article. (2) RH and $\mathrm{EH}$ are the senior academic staff members that supervised the research and directly contributed with advise and improvement recommendations to the storyline and the solid argumentation within this article. (3) MV performed interviews with relevant stakeholders to obtain data needed for the Danube case study and provided feedback on the manuscript. (4) IB is a senior academy staff member that not only provided the contact to obtain the data along the Danube corridor, but also actively reflected his expe tise of Danube navigation to ensure that this manuscript accurately reflects Danube operations. All authors read and approved the final manuscript.

\section{Funding}

The research leading to these results has been conducted within the NOVIMAR project (NOVel Iwt and MARitime transport concepts) and received funding from the European Union Horizon 2020 Program under grant agreement $n^{\circ} 723009$

\section{Availability of data and materials}

Not Applicable. All information needed to reproduce the results are provided in this article and the "Appendix".

\section{Declarations}

\section{Competing interests}

The authors have no competing interests to declare.

\begin{abstract}
Author details
'Delft University of Technology, Mekelweg 2, 2628 CD Delft, The Netherlands. ${ }^{2}$ University of Antwerp, Prinsstraat 13, 2000 Antwerp, Belgium. ${ }^{3}$ University of Belgrade, Kraljice Marije 16, 11120 Belgrade 35, Serbia.
\end{abstract}

Received: 8 July 2021 Accepted: 13 February 2022

Published online: 25 February 2022

\section{References}

1. Al Enezy, O., van Hassel, E., Sys, C., \& Vanelslander, T. (2017). Developing a cost calculation model for inland navigation In Research in transportation business \& management. (pp. 64-67). https://doi.org/10.1016/J.RTBM. 2017.02.006

2. Argonics Gmbh. (2017). ArgoTrackPilot. http://www.argonics.de/en/argoT rackPilot

3. Bačkalić, T., Maslarić, M., \& Bojic, S. (2015). Analysis of possible draught size of container vessels on the lower Danube. International Journal of Mechanical, Aerospace, Industrial, Mechatronic and Manufacturing Engineering, 9(7), 1147-1179.

4. Beelen, M. (2011). Structuring and modelling decision making in the inland navigation sector. Universiteit Antwerpen.

5. BMVI. (2019). Inland waterway transport materplan. In Inland Waterway Transport. https://doi.org/10.4324/9781315739083

6. Caterpillar. (2001). Caterpillar Marine Propulsion Engine $3406 E$.

7. CCNR. (2016). Regulations for Rhine navigation personnel (rpn).

8. CCNR. (2017). Waterway Profile of the Rhine. http://www.ccr-zkr.org/files/ documents/infovoienavigable/Wasserstrassenprofil_en.pdf

9. CCNR. (2019). Inland Navigation in Europe Market Observation Annual Report 2019.

10. Caris, A., Limbourg, S., Macharis, C., Lier, T., \& van Cools, M. (2014). Integration of inland waterway transport in the intermodal supply chain: A taxonomy of research challenges. In Journal of Transport Geography, 41, 126-136. https://doi.org/10.1016/j.jtrangeo.2014.08.022

11. Charles, L. (2008). Sea-river shipping competitiveness and its geographical market area for the Rhône-Saône corridor. Journal of Transport Geography, 16(2), 100-116. https://doi.org/10.1016/j.jtrangeo.2007.04.003

12. Chen, L., Haseltalab, A., Garofano, V., \& Negenborn, R. (2019). Eco-VTF: Fuel-efficient vessel train formations for all-electric autonomous ships. In 18th European control conference (ECC) (pp. 2543-2550). https://doi.org/ 10.23919/ECC.2019.8796033

13. Chen, L., Huang, Y, Zheng, H., Hopman, H, Negenborn, R. (2019). Cooperative multi-vessel systems in urban waterway networks. IEEE Transactions on Intelligent Transportation Systems, 66, 1-14.

14. Chen, L., Negenborn, R., \& Hopman, H. (2018). Intersection crossing of cooperative multi-vessel systems. IFAC-PapersOnLine, 51(9), 379-385. https://doi.org/10.1016/j.ifacol.2018.07.062

15. Colling, A. P., \& Hekkenberg, R. G. (2020). Waterborne platooning in the short sea shipping sector. Transportation Research Part C: Emerging Technologies. https://doi.org/10.1016/j.trc.2020.102778

16. Colling, A., Van Hassel, E., \& Hekkenberg, R. (2021). Waterborne platoon on the lower Rhine. European Journal of Transport and Infrastructure Research, 21(2), 71-94. https://doi.org/10.18757/ejtir.2021.21.2.5469

17. Danube Commission. (2017). Danube navigation statistics in 2015-2016 (Issue November). https://www.danubecommission.org/dc/en/danubenavigation/danube-navigation-statistics/

18. Danube Commission. (2018). 90th session of the Danube Commission: Market observation for Danube navigation results in 2017.

19. de Leeuw van Weenen, R., Ferencz, J., Chin, S., \& Van Der Geest, W. (2013). Living and working conditions in inland navigation in Europe. In International Labour Office Geneva (Issue 297). 
20. Dragin, A. S., Djurdjev, B. S., Armenski, T., Jovanovic, T., Pavic, D., IvkovDzigurski, A., Kosic, K., \& Favro, S. (2014). Analysis of the labour force composition on cruisers: The Danube through Central and Southeast Europe. Journal of Transport Geography, 39, 62-72. https://doi.org/10. 1016/j.jtrangeo.2014.06.013

21. European Commission. (2017). Study on Rhine-Danube TEN-T core network corridor-phase 2. December. https://ec.europa.eu/transport/sites/ transport/files/rhd_study_2017_final_report.pdf

22. Eurostat. (2021). https://ec.europa.eu/eurostat/databrowser/view/tran_ hv_frmod/default/table?lang=en

23. Eurostat. (2020). Number of inland waterway transport enterprises by num ber of vessels (2003-2012). https://ec.europa.eu/eurostat/data/database? node_code=iww_ec_ent_n

24. Ghaderi, H. (2019). Autonomous technologies in short sea shipping: Trends, feasibility and implications. Transport Reviews, 91(1), 152-173. https://doi.org/10.1080/01441647.2018.1502834

25. Grønsedt, P. (2014). Financial cost benefit-analysis of maritime transport through the Northern Sea Route.

26. Guesnet, T., Deußner, R., Kirchmayr-Novak, S., Strasser, G., Bačkalov, I., Hofman, M., Simić, A., Radojčić, D., Giuglea, V., \& lonas, O. (2013). Innovative Danube vessel.

27. Hall, D. R. (1993) Impacts of economic and political transition on the transport geography of Central and Eastern Europe. In Journal of Transport Geography, 1(1), 20-35. https://doi.org/10.1016/0966-6923(93)90035-X

28. Hekkenberg, R. G. (2013). Inland Ships for Efficient Transport Chains. In Technische Universiteit Delft.

29. Hekkenberg, R. G., \& Colling, A. P. (2020). NOVIMAR Deliverable 1. 5: Intermediate Assessment.

30. Holtrop, J., \& Mennen, G. G. (1982). An approximate power prediction method. International Shipbuilding Progress, 25, 335-366. https://doi.org/ $10.4271 / 971010$

31. Konings, R., \& Ludema, M. (2000). The competitiveness of the river-sea transport system: Market perspectives on the United Kingdom-Germany corridor. Journal of Transport Geography, 8(3), 221-228. https://doi.org/10. 1016/S0966-6923(00)00015-6

32. Kretschmann, L., Rodseth, O., Sage Fuller, B., Noble, H., Horahan, J., \& McDowell, H. (2015). MUNIN D9. 3: Quantitative assessment.

33. Lyridis, D. V., Psaraftis, H. N., Ventikos, N. P., \& Zacharioudakis, P. G. (2005). Cost-benefit analysis for ship automation retrofit: The case of icebreaker cost-benefit analysis for ship automation retrofit: The case of icebreaker frej. Maritime Technolgy, 42, 113-124

34. Maverick \& STC-Nestra. (2015). Versterking van de marketstructuur in de binnenvaart.

35. Meersman, H., Moschouli, E., Nanwayboukani, L., Sys, C., \& Van Hassel, E. (2020). Evaluating the performance of the vessel train concept. European Transport Research Review, 9, 66.

36. Nilson, E., Lingemann, I., Klein, B., \& Krahe, P. (2013). ECCONET Deliverable 1.4: Impact of Hydrological change on Navigation conditions (Issue March).

37. Notteboom, T., Yang, D., \& Xu, H. (2020). Container barge network development in inland rivers: A comparison between the Yangtze River and the Rhine River. Transportation Research Part A Policy and Practice, 132 587-605. https://doi.org/10.1016/j.tra.2019.10.014

38. NOVIMAR. (2017). NOVIMAR and the vessel train concept. https://novimar. eu/concept/

39. PINE. (2004). Prospects of Inland navigation within the enlarged Europe (Issue March).

40. PROMINENT. (2015). D1.1 List of operational profiles and fleet families.

41. QUOVADIS. (2018). Loontabel CAO Binnenvaart 2018. https://quovadispe rsoneel.nl/loontabel-cao-binnenvaart-2018/

42. Radojcic, D. (2005). Danube Intermodal Ships - Container vs. Ro-Ro. The Ship in Intermodal Transport, 26th Duisburg Colloquium, June.

43. Rogerson, S., Santén, V., Svanberg, M., Williamsson, J., \& Woxenius, J. (2020). Modal shift to inland waterways: Dealing with barriers in two Swedish cases. International Journal of Logistics Research and Applications, 23(2),195-210. https://doi.org/10.1080/13675567.2019.1640665

44. Serbian Ministry of Construction Transport and Infrastructure. (2020). Authority for Determination of the Seaworthiness: SHIPS-The Electronic Register of issued documents 2020.

45. Sys Christa, Van de Voorde Eddy, Vanelslander Thierry, van Hassel Edwin (2020). Pathways for a sustainable future inland water transport: a case study for the European inland navigation sector. In Case studies on transport policy/WCTR Society, 8(3), 686-699. https://doi.org/10.1016/J. CSTP.2020.07.013

46. UNECE. (2019). Recommendations on harmonized europe-wide technical requirements for inland navigation vessels (Resolution No.61). In recommendations on harmonized Europe-wide Technical Requirements for Inland Navigation Vessels (Issue 61). https://doi.org/10.18356/22c5ac44-en

47. Verberght, E. (2019). INN-IN Innovative Inland Navigation.

48. Verberght, E, \& van Hassel, E. (2019). The automated and unmanned inland vessel. In Journal of Physics: Conference Series, 1357(1), 1-12. https:// doi.org/10.1088/1742-6596/1357/1/012008

49. ViaDonau. (2019). Manual on Danube Navigation. In ViaDonau. Www.viadonau.org

50. Zeng, Q., Hekkenberg, R., \& Thill, C. (2019). On the viscous resistance of ships sailing in shallow water. Ocean Engineering, 190, 106434.

\section{Publisher's Note}

Springer Nature remains neutral with regard to jurisdictional claims in published maps and institutional affiliations.

\section{Submit your manuscript to a SpringerOpen ${ }^{\odot}$ journal and benefit from:}

- Convenient online submission

- Rigorous peer review

- Open access: articles freely available online

- High visibility within the field

- Retaining the copyright to your article

Submit your next manuscript at $\boldsymbol{\nabla}$ springeropen.com 